\title{
Deletion of CD14 Attenuates Alzheimer's Disease Pathology by Influencing the Brain's Inflammatory Milieu
}

\author{
Erin G. Reed-Geaghan, Quillan W. Reed, Paige E. Cramer, and Gary E. Landreth \\ Alzheimer Research Laboratory, Department of Neurosciences, School of Medicine, Case Western Reserve University, Cleveland, 0 hio 44106
}

\begin{abstract}
Alzheimer's disease $(\mathrm{AD})$ is characterized by the deposition of $\beta$-amyloid $(\mathrm{A} \beta)$-containing plaques within the brain that is accompanied by a robust microglial-mediated inflammatory response. This inflammatory response is reliant upon engagement of innate immune signaling pathways involving the toll-like receptors (TLRs). Studies assessing the roles of TLRs in AD pathogenesis have yielded conflicting results. We have assessed the roles of the TLRs through genetic inactivation of the TLR2/4 coreceptor, CD14, in a transgenic murine model of AD. Transgenic mice lacking CD14 exhibited reduced insoluble, but not soluble, levels of A $\beta$ at 7 months of age. This corresponded with decreased plaque burden resulting from a reduction in number and size of both diffuse and thioflavin S-positive plaques and an overall reduction in the number of microglia. These findings are inconsistent with the established actions of these receptors. Moreover, loss of CD14 expression was associated with increased expression of genes encoding the proinflammatory cytokines $\operatorname{Tnf} \alpha$ and If $\gamma$, decreased levels of the microglial/macrophage alternative activation markers Fizz1 and Ym1, and increased expression of the anti-inflammatory gene $\mathrm{Il}-10$. Thus, the loss of CD14 resulted in a significant change in the inflammatory environment of the brain, likely reflecting a more heterogeneous population of microglia within the brains of the animals. The reduction in plaque burden was not a result of changes in the expression of various $\mathrm{A} \beta$ degrading enzymes or proteins associated with $\mathrm{A} \beta$ clearance. These data suggest that CD14 is a critical regulator of the microglial inflammatory response that acts to modulate $\mathrm{A} \beta$ deposition.
\end{abstract}

\section{Introduction}

Alzheimer's disease (AD) has a robust inflammatory component owing to the microglial response to fibrillar forms of $\beta$-amyloid $(\mathrm{fA} \beta)$ that are deposited in the diseased brain (Akiyama et al., 2000; Lucin and Wyss-Coray, 2009). Microglia, the brain's tissue macrophages, are representatives of the innate immune system. Their exposure to fA $\beta$ stimulates canonical host-defense mechanisms, resulting in the elaboration of an array of immune mediators including reactive oxygen and nitrogen species, chemokines, and inflammatory cytokines. Traditionally, microglial phenotype was viewed as dichotomous, with "resting" microglia converting upon stimulation into a "classically activated" state, termed M1 activation (Martinez et al., 2009). It has recently been appreciated that microglia/macrophages are heterogeneous with respect to activation status, exhibiting a spectrum of diverse and plastic phenotypes including those associated with the tissue maintenance and repair (Town et al., 2005; Mosser and Edwards, 2008). These latter states, termed "alternative" (M2) activation, arise through the action of anti-inflammatory cytokines. The M2 state has been subclassified into M2a, M2b, and $\mathrm{M} 2 \mathrm{c}$ states, largely based on gene expression signatures that typify

Received May 24, 2010; revised July 2, 2010; accepted Aug. 12, 2010.

This work was supported by the National Institutes of Health (AG16047) and the Blanchette Hooker Rockefeller Foundation. E.G.R.-G. was supported by a predoctoral Ruth L. Kirschstein National Research Service Award (F31NS057867) and a Neuroscience Training Grant (5 T32 AG0071) from the National Institute of Neurological Disorders and Stroke.

Correspondence should be addressed to Gary E. Landreth, Department of Neuroscience, Case Western Reserve University, School of Medicine, 10900 Euclid Avenue, Cleveland, 0H 44106-4928. E-mail: gel2@case.edu.

DOI:10.1523/JNEUROSCI.2637-10.2010

Copyright $\odot 2010$ the authors $\quad$ 0270-6474/10/3015369-05\$15.00/0 distinct functional states of these cells. The brains of both $\mathrm{AD}$ patients and mouse models of the disease exhibit increased expression of both M1 and M2 activation markers (Colton et al., 2006). Whether there is a disease-related progression from an M1 to M2 status (Colton et al., 2006) or the reverse (Jimenez et al., 2008) is controversial, and resolution of this problem is hampered by the inability to perform phenotypic analysis at the cellular level.

Toll-like receptors (TLRs) and their coreceptors allow the innate immune system to detect pathogens and mount a defensive response. Microglia detect and respond to $\mathrm{fA} \beta$ through a multicomponent receptor complex comprised of CD36, SRA, CD47, and the $\alpha_{6} \beta_{1}$ integrin (Moore et al., 2002; Bamberger et al., 2003), which also includes CD14, TLR2, TLR4, and TLR6 (for review, see Landreth and Reed-Geaghan, 2009). While in vitro studies have provided definitive evidence for an obligatory role for these receptors in classical activation of microglia in response to $\mathrm{fA} \beta$, the situation in vivo is much less clear. Murine models of AD with defective TLR4 signaling exhibited increased plaque burden (Tahara et al., 2006), while TLR2null mice had delayed plaque deposition through 6 months of age (Richard et al., 2008). Thus, it remains uncertain what roles TLR signaling has within the $\mathrm{AD}$ brain.

We have investigated the role of CD14 in a murine model of AD, as it acts as a coreceptor for both TLR2 and TLR4 and perturbs the function of both of these receptors. CD14-deficient animals had reduced plaque burden at 7 months of age. Deletion of CD14 altered the inflammatory status of the brain, with reduced microgliosis and CD45 immunoreactivity that was accompanied by enhanced expression of both M1 and M2 activation markers. These data suggest critical roles for TLRs and their coreceptors in disease progression and development of microglial phenotypic heterogeneity. 


\section{Materials and Methods}

Animals. B6C3-Tg(APPswe, PSEN1dE9)85Dbo/J mice (Jankowsky et al., 2001) were obtained from The Jackson Laboratory. Hemizygous transgenic mice were mated to $\mathrm{CD} 14^{-l-}$ mice obtained from The Jackson Laboratory. Resulting transgenic $\mathrm{CD} 14^{+/-}$males were mated to nontransgenic $\mathrm{CD} 14^{+/-}$females to obtain nontransgenic and transgenic $\mathrm{CD} 14^{+/+}$and $\mathrm{CD} 14^{-/-}$animals. Females were killed at 28 weeks of age and processed for histological or biochemical analysis.

Tissue collection. Animals were anesthetized and perfused with PBS followed by $4 \%$ paraformaldehyde in phosphate buffer. For biochemical analysis, animals were killed by cervical dislocation, and the brain was immediately removed, bisected along the midline, frozen, and stored at $-80^{\circ} \mathrm{C}$ until use.

Immunohistochemistry. Tissue sections were rehydrated and endogenous peroxidase activity was quenched with $3 \% \mathrm{H}_{2} \mathrm{O}_{2}$ in methanol for 30 min. For $6 \mathrm{E} 10$ staining, sections were pretreated with $70 \%$ formic acid, blocked with $5 \%$ normal goat serum, and incubated overnight in primary antibody (6E10, Signet Laboratories); Ibal (Wako); CD45 (AbD Serotec); GFAP (Dako). Biotinylated-secondary antibodies were detected with an avidin-biotin-peroxidase complex (ABC Kit, Vector Laboratories) and diaminobenzidine (Vector Laboratories). Sections were counterstained with hematoxylin. For immunofluorescent staining, slides were incubated with the appropriate Alexa-conjugated secondary antibodies. Thioflavin $\mathrm{S}$ staining was performed by rehydrating sections and staining with $1 \%$ thioflavin S (Sigma). Slides were coverslipped with Vectastain containing propidium iodide (Vector Laboratories). Image analysis was performed using Image-Pro Plus 6.0 software (Media Cybernetics). For each mouse, non-overlapping images of the cortex from the midline laterally to the secondary somatosensory cortex were analyzed. Four sections/slide and four slides/animal spaced evenly from $200 \mu \mathrm{m}$ anterior to CA3 to the caudal extent of the hippocampus were analyzed.

$A \beta$ ELISA. Hemibrains were homogenized in tissue homogenizing buffer (250 mm sucrose, 20 mm Tris, 1 mm EDTA, 1 mm EGTA in DEPC water) containing protease inhibitor cocktail (Sigma) using a glass-onglass homogenizer at $4^{\circ} \mathrm{C}$. $\mathrm{A} \beta$ was extracted sequentially using diethylamine and formic acid. ELISAs for $\mathrm{A} \beta_{1-40}$ and $\mathrm{A} \beta_{1-42}$ were performed as described previously (Jiang et al., 2008).

RNA extraction, reverse transcription, and quantitative PCR. Total RNA was isolated from hemibrains using RNA-Bee (Tel-Test, Inc) followed by an RNeasy Mini Spin Column (Qiagen). Complementary DNA (cDNA) was synthesized from RNA samples using QuantiTect Reverse Transcription kit (Qiagen) using $0.5 \mu \mathrm{g}$ of total RNA. Fourteen cycles of cDNA preamplification was performed using TaqMan PreAmp Master Mix (Applied Biosystems). Preamplified cDNA was used for qPCR with the StepOne Plus Real Time PCR system (Applied Biosystems) in a $20 \mu \mathrm{l}$ reaction for 40 cycles. Primers with FAM or VIC probes were from Applied Biosystems. Analysis of gene expression was performed using the comparative $\mathrm{C}_{\mathrm{T}}$ method (Schmittgen and Livak, 2008).

Statistical analyses. All values reported are the average \pm SEM. Statistical significance was determined using the Student's $t$ test (GraphPad Prism 5.0 software).

\section{Results}

\section{Deletion of CD14 reduces A $\beta$ burden}

CD14 plays a critical role in the activation of microglia by fA $\beta$ (Fassbender et al., 2004; Liu et al., 2005; Reed-Geaghan et al., 2009). We sought to determine how loss of CD14 might influence AD pathogenesis by examining an animal model of $\mathrm{AD}$ deficient in this receptor. Deletion of CD14 in the APPswe/PSEN1dE9 mouse $\left(\mathrm{TgCD} 14^{-/-}\right)$had no effect on soluble $\mathrm{A} \beta$, but was associated with a $50 \%$ reduction in insoluble $\mathrm{A} \beta$ (supplemental Fig. $1 A, B$, available at www.jneurosci.org as supplemental material). This was not a consequence of decreased APP expression (supplemental Fig. 1C, available at www.jneurosci.org as supplemental material).

Immunohistochemical analysis of $\mathrm{A} \beta$-immunoreactive plaques, detected using 6E10 to detect both diffuse and dense core plaques, revealed an approximate $50 \%$ reduction in cortical
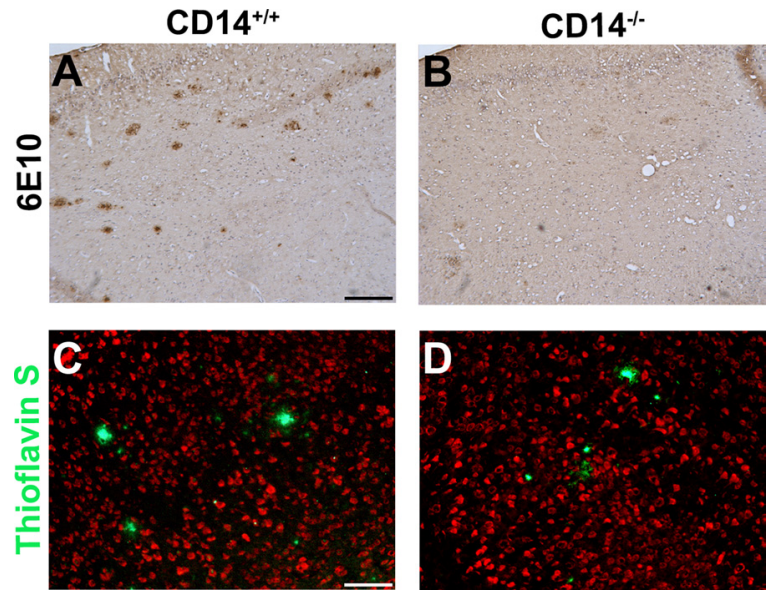

Figure 1. Deletion of $C D 14$ reduces $A \beta$ plaque burden. $A, B$, Cortical 6 E10 immunohistochemistry of TgCD14 ${ }^{+/+}(\boldsymbol{A})$ and $\operatorname{TgCD}_{4}{ }^{-/-}(\boldsymbol{B})$ mice. Scale bar, $400 \mu \mathrm{m}$. C, D, Cortical thioflavin S immunohistochemistry on $\operatorname{TgCD14}^{+/+}(\mathrm{C})$ and $\operatorname{TgCD14}{ }^{-/-}$(D) mice. Scale bar, $100 \mu \mathrm{m}$.

plaque burden in $\mathrm{TgCD} 14^{-/-}$mice $(1.701 \pm 0.1545 \%)$ compared to their TgCD $14^{+/+}$littermates $(3.37 \pm 0.266 \% ; p<$ 0.001 ) (Fig. $1 A, B)$. TgCD $14^{-1-}$ mice had $44 \%$ fewer $6 \mathrm{E} 10$ immunoreactive plaques $(81.35 \pm 5.46$ vs $45.62 \pm 4.25 ; p<$ $0.001)$, with a shift toward smaller plaques (TgCD14 ${ }^{+/+}:<500$ $\mu \mathrm{m}^{2}=38.176 \pm 2.407 \%, 500-1000 \mu \mathrm{m}^{2}=25.257 \pm 1.675 \%$, $>1000 \mu \mathrm{m}^{2}=36.567 \pm 2.001 \%$ vs TgCD $14^{-1-}:<500 \mu \mathrm{m}^{2}=$ $59.780 \pm 3.300 \%, 500-1000 \mu \mathrm{m}^{2}=18.411 \pm 2.132 \%,>1000$ $\left.\mu \mathrm{m}^{2}=21.809 \pm 1.474 \% ; p<0.001, p<0.05, p<0.001\right)$. Cortical dense-core plaques, detected by thioflavin $S$, were reduced $60 \%$ in TgCD $14^{-1-}$ mice $(0.167 \pm 0.011 \%)$ compared to their TgCD $14^{++}$counterparts $(0.419 \pm 0.254 \% ; p<0.001)$ (Fig. 1C,D). The decrease in the number thioflavin $\mathrm{S}$ plaques (72.23 \pm 7.51 vs $37.79 \pm 5.86 ; p<0.05)$ was uniform across all sizes $\left(\mathrm{TgCD} 14^{+/+}:<500 \mu \mathrm{m}^{2}=51.553 \pm 1.630 \%, 500-1000\right.$ $\mu \mathrm{m}^{2}=14.126 \pm 1.018 \%,>1000 \mu \mathrm{m}^{2}=34.321 \pm 0.882 \%$ vs TgCD $14^{-l-}:<500 \mu \mathrm{m}^{2}=56.487 \pm 3.375 \%, 500-1000 \mu \mathrm{m}^{2}=$ $\left.15.206 \pm 1.105 \%,>1000 \mu \mathrm{m}^{2}=28.306 \pm 2.583 \%\right)$.

\section{Deletion of CD14 reduces microglial number and modulates} their activation status

$\mathrm{AD}$ is associated with robust microgliosis and an increase in inflammatory mediators that parallels $\mathrm{A} \beta$ deposition and plaque formation. Microglia surround amyloid plaques in AD brains and in $\mathrm{AD}$ animal models (Akiyama et al., 2000). Microglial abundance, assessed by Ibal immunoreactivity in the cortex, was decreased by $60 \%$ in the $\mathrm{TgCD} 14^{-1-}$ mice $(0.468 \pm 0.113 \%)$ compared to transgenic controls $(1.22 \pm 0.21 ; p<0.05)$ (Fig. $2 A, B)$. There was no difference in area occupied by Iba ${ }^{+}$microglia surrounding 6E10-immunoreactive plaques between genotypes (Fig. $2 C, D$ ). This suggests microglia in TgCD $14^{-/-}$mice still recognize $\mathrm{fA} \beta$ or other plaque components and migrate to and associate with $\mathrm{A} \beta$ plaques.

CD45, a tyrosine phosphatase important in immune signaling, is elevated in microglia of human and mouse AD brains. Importantly, it has been shown to serve as an "off" switch in A $\beta$-induced microglial activation (Tan et al., 2000). Cortical CD45 burden was reduced $50 \%$ in $\mathrm{TgCD} 14^{-1-}$ mice $(0.75 \pm$ $0.11 \%)$ compared to TgCD $14^{+/+}$mice $(1.47 \pm 0.18 \% ; p<0.05)$ (Fig. 2E,F). The traditional interpretation of such data is that microglial CD45 expression is induced upon plaque association. However, it has recently been argued that $\mathrm{CD} 45^{+}$peripheral 

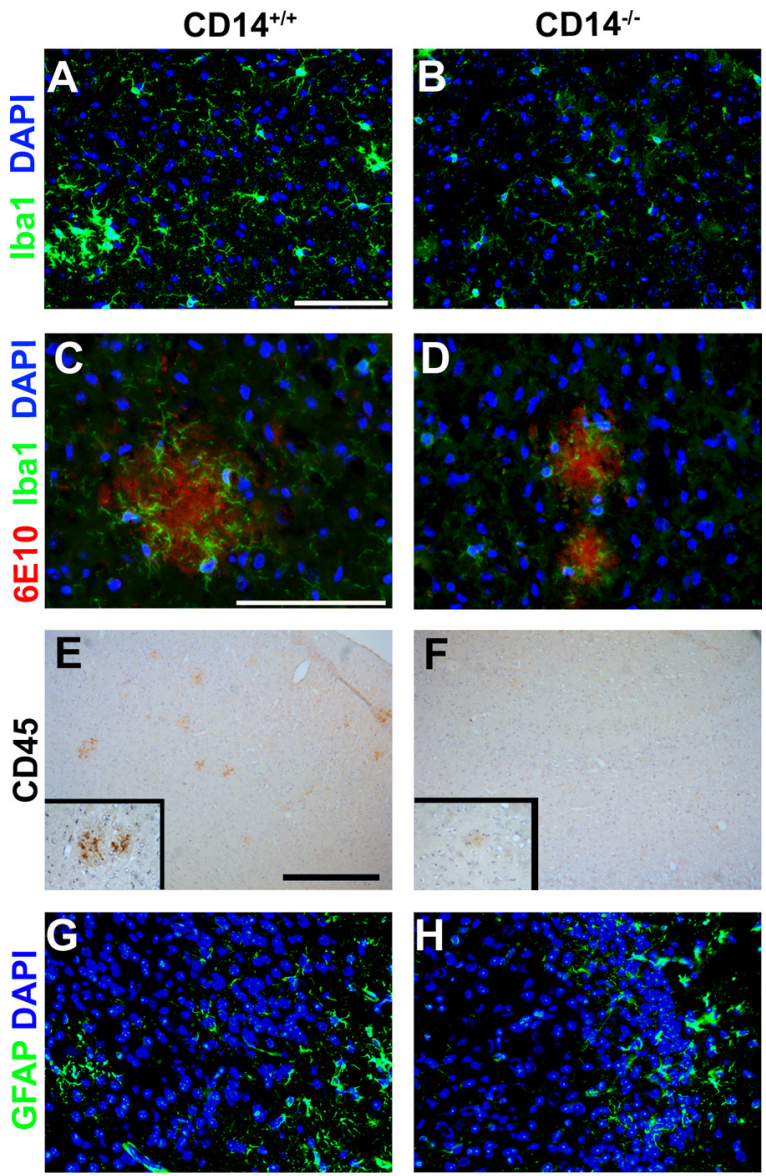

Figure 2. CD14 deletion reduces microglial activation and CD45 without changing plaqueassociated microglia or astrocytes. $\boldsymbol{A}, \boldsymbol{B}$, Cortical lba1 immunohistochemistry of $\operatorname{TgCD} 14^{+1+}$ (A) and $\operatorname{TgCD14}{ }^{-1-}(\boldsymbol{B})$ mice. Scale bar, $50 \mu \mathrm{m}$. C, D, Cortical 6E10 and Iba1 colabeling of $\mathrm{TgCD}_{4}{ }^{+/+}(\boldsymbol{C})$ and $\operatorname{TgCD}_{4}{ }^{-/-}(\boldsymbol{D})$ brains. Scale bar, $50 \mu \mathrm{m} . \boldsymbol{E}, \boldsymbol{F}$, Cortical CD45 immunohistochemistry on $\mathrm{TgCD}_{4}{ }^{+/+}(\boldsymbol{E})$ and $\operatorname{TgCD}^{-1-}(\boldsymbol{F})$ coronal sections. Magnification is $5 \times$ (scale bar, $400 \mu \mathrm{m}$ ); insets are $20 \times$. G, H, Cortical GFAP immunohistochemistry of $\mathrm{TgCD}^{+/+}(\boldsymbol{G})$ and $\operatorname{TgCD}^{-/-}(\boldsymbol{H})$ mice.

monocytes/macrophages infiltrate the $\mathrm{AD}$ brain, and it remains possible that this process is diminished upon CD14 deletion (El Khoury and Luster, 2008). GFAP immunoreactivity was also assessed, and no difference was observed (Fig. 2G,H).

Microglia exhibit a range of different phenotypes. Classi$\mathrm{cal} / \mathrm{M} 1$ activation is associated with the production of Th1 proinflammatory cytokines, an important host defense mechanism associated with elimination of pathogens. APPswe/PSEN1dE9 mice do not show increased levels of inflammatory cytokines until at least 8 months of age (Ruan et al., 2009). We found CD14-deficient transgenic mice exhibited a threefold increase in Tnf $\alpha$ and a nonsignificant twofold elevation in If $n \gamma$ compared to their TgCD $14^{+/+}$littermates (Fig. 3A). There was no change in the expression of $I l-1 \beta, \operatorname{Cox} 2$, or $C c l 2$ (Fig. 3A).

Alternative (M2) activation is associated with the expression of Th2 anti-inflammatory cytokines that are associated with tissue repair function of macrophages. The brains of TgCD14 mice had significantly decreased levels of the M2 marker Ym1. There was a nonsignificant reduction in Fizz1 levels. The M2 activation state is subdivided into M2a, M2b, and M2c subclasses, each with different functions as a result of different cytokine and gene expression profiles. TgCD14 ${ }^{-1-}$ mice exhibited a 2.5 -fold increase in $I l-10$ expression (Fig. $3 B$ ). These studies demonstrate that
A

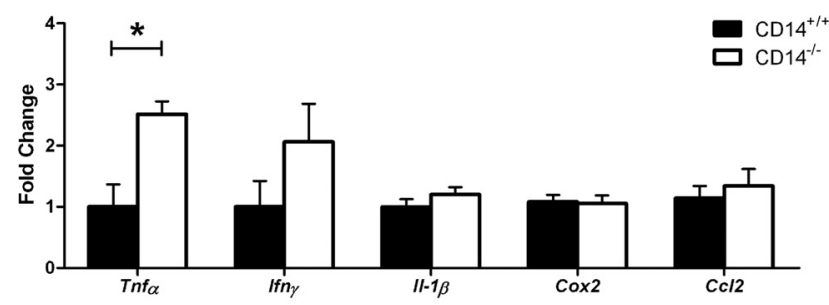

B

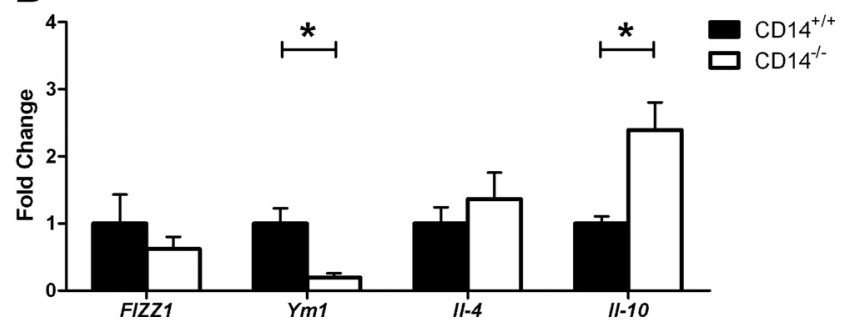

Figure 3. Deletion of CD14 alters the inflammatory environment of the brain. $A, B$, The levels of mRNA for M1 activation proinflammatory cytokines $(\boldsymbol{A})$ or $\mathrm{M} 2$ activation markers and M2related cytokines $(\boldsymbol{B})$ from brain of $\mathrm{TgCD} 14^{+/+}$and $\mathrm{TgCD} 14^{-/-}$mice measured by qPCR. Graph represents mean ( $n>5$ animals/genotype), and error bars represent SEM. ${ }^{*} p<0.05$.

CD14 deletion alters the cytokine profile of the brain and gene expression pattern to a state that is most consistent with the M2b state.

\section{Deletion of CD14 does not result in altered expression of} genes encoding $\mathrm{A} \boldsymbol{\beta}$ degradation enzymes or transport genes We next assessed whether the altered inflammatory environment of TgCD $14^{-/-}$mice would impact the expression of mRNA for $\mathrm{A} \beta$ degrading enzymes or proteins involved in $\mathrm{A} \beta$ clearance. Quantitative PCR of the major A $\beta$ degrading enzymes ide, neprilysin, and $m m p 9$ showed no change in expression upon deletion of CD14 (Fig. 4A). Similarly, other enzymes that degrade A $\beta$, including ACE1, ECE1, ECE2, and the plasminogen system were unchanged (Fig. $4 B$ ). Other genes associated with $\mathrm{A} \beta$ clearance (Lrp1, Abca1, Apoe, C1q, or C3) were unaffected by loss of CD14 (Fig. 4C). These data suggest that the altered inflammatory environment does not change the expression levels of genes associated with $\mathrm{A} \beta$ degradation or clearance, but does not rule out that alterations in enzyme activity may occur.

\section{Discussion}

The primary goal of these studies was to disable TLR2/4 signaling through genetic inactivation of the gene for their coreceptor CD14 and to establish its impact on disease pathogenesis. We report that the absence of CD14 decreases plaque burden and modulates microglial activation status, demonstrating that $\mathrm{fA} \beta$ stimulation of the innate immune response plays critical roles in plaque dynamics. The observation that CD14 deletion resulted in decreased plaque burden was counterintuitive, based on our work and those of others using in vitro models that have documented an obligatory role for CD14 and TLR2/4 for microglia responses to $\mathrm{fA} \beta$. In vitro analysis of microglia has provided clear and consistent evidence that TLR2/4/6 and their coreceptors CD14 and CD36 are necessary for the recognition, binding, and subsequent activation of intracellular signaling cascades subserving a broad range of biological effects of $\mathrm{fA} \beta$ on these cells (for review, see Landreth and Reed-Geaghan, 2009). However, the roles of the TLRs in the AD brain are unclear owing to a diverse array of conflicting in vivo data (Morgan et al., 2005). Expression levels of TLRs and CD14 are elevated in the brains of AD patients 
A

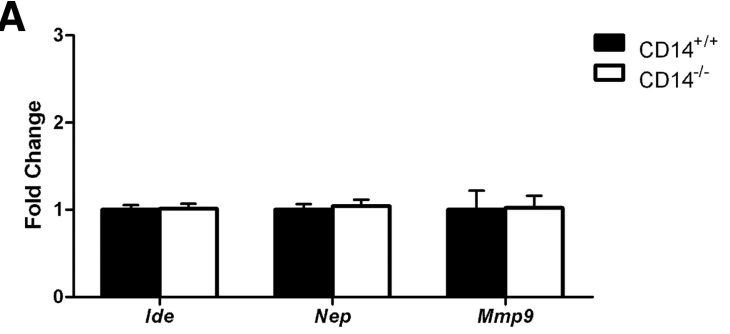

B

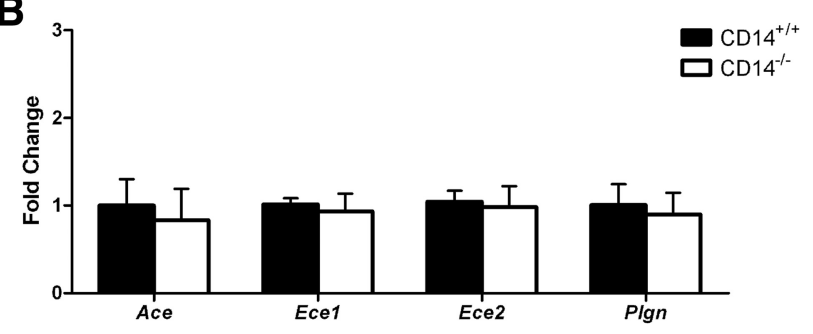

C

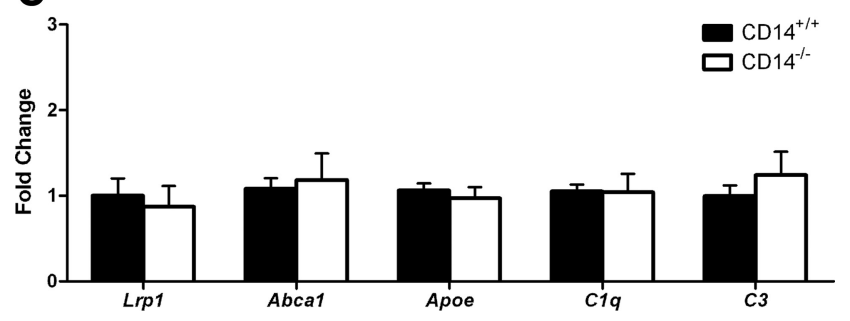

Figure 4. The absence of $C D 14$ does not change the expression of $A \beta$ degrading enzymes or genes associated with $A \beta$ clearance. $\boldsymbol{A}-\boldsymbol{C}$, Quantitative $P C R$ results from the brains of $\mathrm{Tg}$ CD14 ${ }^{+/+}$and $\operatorname{TgCD} 14^{-/-}$mice for $A \beta$ degrading enzymes $(\boldsymbol{A}, \boldsymbol{B})$ or $A \beta$ clearance proteins (C). Graph represents mean ( $n>5$ animals/genotype), and error bars represent SEM.

and in animal models of the disease (for review, see Landreth and Reed-Geaghan, 2009). In humans, inactivating TLR4 mutations are associated with decreased risk for AD (Minoretti et al., 2006). Genetic inactivation of TLR4 in a mouse model of AD was associated with increased plaque burden in mice greater than 1 year of age (Tahara et al., 2006). In contrast, knock-out of TLR2 in a mouse model of $\mathrm{AD}$ resulted in decreased levels of plaque deposition for up to 6 months, but was normalized in older animals (Richard et al., 2008). Acute activation of TLR4/CD14 with lipopolysaccharide (LPS), administered systemically (Quinn et al., 2003) or injected into the brain (DiCarlo et al., 2001; Herber et al., 2004; Malm et al., 2005), was associated with microglial activation and $\mathrm{A} \beta$ plaque clearance. However, sustained exposure to LPS, delivered either systemically (Sheng et al., 2003; McAlpine et al., 2009) or injected into the brain (Qiao et al., 2001), induced intraneuronal $\mathrm{A} \beta$ deposition and accelerated/enhanced plaque deposition, supporting the view that chronic microglial activation contributes to disease progression and severity and alters the kinetics of plaque deposition.

Microglial-mediated inflammation has been argued to be a critical contributor to AD pathogenesis. Microglia number in the brain increase in proportion to the plaque dimension, possibly to regulate plaque dynamics through $\mathrm{A} \beta$ clearance and phagocytosis. However, the accumulation of deposited forms of amyloid illustrate that endogenous microglia are inefficient in plaque removal and are unable to suppress plaque formation (Grathwohl et al., 2009). It is evident that acute TLR-mediated microglial activation is sufficient to provoke the clearance of plaques from the brain (DiCarlo et al., 2001; Quinn et al., 2003; Herber et al., 2004; Liu et al., 2005; Malm et al., 2005; Tahara et al., 2006; Richard et al., 2008). Moreover, the persis- tence of classically activated microglia and their secretion of cytokines and other immune mediators contributes to the well documented proinflammatory milieu in the $\mathrm{AD}$ brain that acts to functionally inactivate the phagocytic machinery (KoenigsknechtTalboo and Landreth, 2005).

Despite an overall reduction in plaque burden in the CD14deficient animals, the remaining plaques were invested with abundant microglia. These data suggest that microglia can detect and respond to amyloid-containing plaques in the absence of CD14. One conclusion is that CD14 is not an obligatory receptor mediating these effects and the in vitro data have been misleading, or that other constituents of the plaque acting through other receptors may subserve these effects. An alternative view of these data arises from the recent appreciation that macrophages can be recruited into the brain from the peripheral circulation (Simard et al., 2006; El Khoury and Luster, 2008; Town et al., 2008). These infiltrating cells are CD $45^{\text {hi }}$, whereas local, resident microglia are CD $45^{\text {low }}$. It is possible that in the absence of CD14-mediated signaling, there is no additional recruitment of peripheral monocytes/macrophages into the brain.

The innate immune system has evolved to allow cellautonomous responses to pathogens. Macrophages and microglia can exhibit a broad array of phenotypes reflective of the influences of their local environment as well as a consequence of their participation in a coordinated genetic program linking classical host defense mechanisms to tissue repair. These latter functions have been dubbed "alternative" or M2 activation (Martinez et al., 2009) using a widely used nomenclature that identifies generally anti-inflammatory actions of these cells that accompany resolution of inflammation. Indeed, it has been postulated that the conversion to an alternatively activated state arose as an adaptive response to tissue resident parasites (Martinez et al., 2009), and this may be relevant to the AD brain in which amyloid deposits persist over time. Alternative/M2 activation is reflective of a Th2-like response. It is important to appreciate that the M1/M2 designations do not capture the genuine complexity of this population of cells, which exhibits a broad spectrum of phenotypes that defy conventional classifications (Town et al., 2005; Mosser and Edwards, 2008).

In the $\mathrm{AD}$ brain and its murine models, microglia comprise a heterogeneous population of cells, with plaque-associated microglia exhibiting quite different phenotypes and activation states from those found elsewhere in the brain parenchyma, and there is evidence for both M1 and M2 gene expression (Colton et al., 2006). We hypothesized that deletion of CD14 would prevent M1 activation, and shift microglia to more alternatively activated states. TgCD $14^{-1-}$ animals had more Tnf $\alpha$ and Ifn $\gamma$ than TgCD $14^{+/+}$mice, suggesting that CD14-deletion enhances or accelerates the classic inflammatory response in $\mathrm{A} \beta$. It is also possible that loss of TLRs alters the functionality of the microglia. Recently, it has been reported that CD14 acts to constrain the actions of TLR2, because in the absence of CD14, a more robust TLR2-stimulated response is generated (Sahay et al., 2009), consistent with our detection of elevated expression of a subset of inflammatory cytokines in CD14-null mice. These data suggest that CD14 negatively modulates TLR signaling in a subpopulation of microglia. Coincident with increased M1 activation markers, there was a twofold decrease in the M2 marker Ym1. Paradoxically, the M2-associated cytokine Il-10 increased twofold. Significantly, Town et al. (2008) have shown reduced cerebral amyloidosis in concert with increased brain $I L-10$ mRNA levels. This cytokine profile is similar to the M2b activation state. Overall, loss of CD14 appears to 
allow a shift the activation state of microglia in the $\mathrm{AD}$ brain to one that is more immunoregulatory.

The present study provides evidence that CD14 modulates the innate immune response to an M2 state that is associated with reduced plaque deposition. The mechanisms through which plaque burden is reduced are unresolved. There is recent evidence that conversion of macrophages into an M2 state is associated with enhanced phagocytosis (Mukundan et al., 2009; Rébé et al., 2009), and it is important to formally test this hypothesis. These findings provide an understanding of CD14-controlled inflammatory processes of the $\mathrm{AD}$ brain, facilitating the development of effective therapeutic strategies to treat AD.

\section{References}

Akiyama H, Barger S, Barnum S, Bradt B, Bauer J, Cole GM, Cooper NR, Eikelenboom P, Emmerling M, Fiebich BL, Finch CE, Frautschy S, Griffin WS, Hampel H, Hull M, Landreth G, Lue L, Mrak R, Mackenzie IR, McGeer PL, et al. (2000) Inflammation and Alzheimer's disease. Neurobiol Aging 21:383-421.

Bamberger ME, Harris ME, McDonald DR, Husemann J, Landreth GE (2003) A cell surface receptor complex for fibrillar $\beta$-amyloid mediates microglial activation. J Neurosci 23:2665-2674.

Colton CA, Mott RT, Sharpe H, Xu Q, Van Nostrand WE, Vitek MP (2006) Expression profiles for macrophage alternative activation genes in $\mathrm{AD}$ and in mouse models of AD. J Neuroinflammation 3:27.

DiCarlo G, Wilcock D, Henderson D, Gordon M, Morgan D (2001) Intrahippocampal LPS injections reduce Abeta load in APP+PS1 transgenic mice. Neurobiol Aging 22:1007-1012.

El Khoury J, Luster AD (2008) Mechanisms of microglia accumulation in Alzheimer's disease: therapeutic implications. Trends Pharmacol Sci 29:626-632.

Fassbender K, Walter S, Kühl S, Landmann R, Ishii K, Bertsch T, Stalder AK, Muehlhauser F, Liu Y, Ulmer AJ, Rivest S, Lentschat A, Gulbins E, Jucker M, Staufenbiel M, Brechtel K, Walter J, Multhaup G, Penke B, Adachi Y, et al. (2004) The LPS receptor (CD14) links innate immunity with Alzheimer's disease. FASEB J 18:203-205.

Grathwohl SA, Kälin RE, Bolmont T, Prokop S, Winkelmann G, Kaeser SA, Odenthal J, Radde R, Eldh T, Gandy S, Aguzzi A, Staufenbiel M, Mathews PM, Wolburg H, Heppner FL, Jucker M (2009) Formation and maintenance of Alzheimer's disease beta-amyloid plaques in the absence of microglia. Nat Neurosci 12:1361-1363.

Herber DL, Roth LM, Wilson D, Wilson N, Mason JE, Morgan D, Gordon MN (2004) Time-dependent reduction in Abeta levels after intracranial LPS administration in APP transgenic mice. Exp Neurol 190:245-253.

Jankowsky JL, Slunt HH, Ratovitski T, Jenkins NA, Copeland NG, Borchelt DR (2001) Co-expression of multiple transgenes in mouse CNS: a comparison of strategies. Biomol Eng 17:157-165.

Jiang Q, Lee CY, Mandrekar S, Wilkinson B, Cramer P, Zelcer N, Mann K, Lamb B, Willson TM, Collins JL, Richardson JC, Smith JD, Comery TA, Riddell D, Holtzman DM, Tontonoz P, Landreth GE (2008) ApoE promotes the proteolytic degradation of Abeta. Neuron 58:681-693.

Jimenez S, Baglietto-Vargas D, Caballero C, Moreno-Gonzalez I, Torres M, Sanchez-Varo R, Ruano D, Vizuete M, Gutierrez A, Vitorica J (2008) Inflammatory response in the hippocampus of PS1M146L/APP751SL mouse model of Alzheimer's disease: age-dependent switch in the microglial phenotype from alternative to classic. J Neurosci 28:11650-11661.

Koenigsknecht-Talboo J, Landreth GE (2005) Microglial phagocytosis induced by fibrillar $\beta$-amyloid and IgGs are differentially regulated by proinflammatory cytokines. J Neurosci 25:8240-8249.

Landreth GE, Reed-Geaghan EG (2009) Toll-like receptors in Alzheimer's disease. Curr Top Microbiol Immunol 336:137-153.

Liu Y, Walter S, Stagi M, Cherny D, Letiembre M, Schulz-Schaeffer W, Heine H, Penke B, Neumann H, Fassbender K (2005) LPS receptor (CD14): a receptor for phagocytosis of Alzheimer's amyloid peptide. Brain 128:1778-1789.

Lucin KM, Wyss-Coray T (2009) Immune activation in brain aging and neurodegeneration: too much or too little? Neuron 64:110-122.

Malm TM, Koistinaho M, Pärepalo M, Vatanen T, Ooka A, Karlsson S, Koistinaho J (2005) Bone-marrow-derived cells contribute to the recruitment of microglial cells in response to beta-amyloid deposition in APP/PS1 double transgenic Alzheimer mice. Neurobiol Dis 18:134-142.
Martinez FO, Helming L, Gordon S (2009) Alternative activation of macrophages: an immunologic functional perspective. Annu Rev Immunol 27:451-483.

McAlpine FE, Lee JK, Harms AS, Ruhn KA, Blurton-Jones M, Hong J, Das P, Golde TE, LaFerla FM, Oddo S, Blesch A, Tansey MG (2009) Inhibition of soluble TNF signaling in a mouse model of Alzheimer's disease prevents pre-plaque amyloid-associated neuropathology. Neurobiol Dis 34:163-177.

Minoretti P, Gazzaruso C, Vito CD, Emanuele E, Bianchi M, Coen E, Reino M, Geroldi D (2006) Effect of the functional toll-like receptor 4 Asp299Gly polymorphism on susceptibility to late-onset Alzheimer's disease. Neurosci Lett 391:147-149.

Moore KJ, El Khoury J, Medeiros LA, Terada K, Geula C, Luster AD, Freeman MW (2002) A CD36-initiated signaling cascade mediates inflammatory effects of beta-amyloid. J Biol Chem 277:47373-47379.

Morgan D, Gordon MN, Tan J, Wilcock D, Rojiani AM (2005) Dynamic complexity of the microglial activation response in transgenic models of amyloid deposition: implications for Alzheimer therapeutics. J Neuropathol Exp Neurol 64:743-753.

Mosser DM, Edwards JP (2008) Exploring the full spectrum of macrophage activation. Nat Rev Immunol 8:958-969.

Mukundan L, Odegaard JI, Morel CR, Heredia JE, Mwangi JW, RicardoGonzalez RR, Goh YP, Eagle AR, Dunn SE, Awakuni JU, Nguyen KD, Steinman L, Michie SA, Chawla A (2009) PPAR-delta senses and orchestrates clearance of apoptotic cells to promote tolerance. Nat Med $15: 1266-1272$.

Qiao X, Cummins DJ, Paul SM (2001) Neuroinflammation-induced acceleration of amyloid deposition in the APPV717F transgenic mouse. Eur J Neurosci 14:474-482.

Quinn J, Montine T, Morrow J, Woodward WR, Kulhanek D, Eckenstein F (2003) Inflammation and cerebral amyloidosis are disconnected in an animal model of Alzheimer's disease. J Neuroimmunol 137:32-41.

Rébé C, Raveneau M, Chevriaux A, Lakomy D, Sberna AL, Costa A, Bessède G, Athias A, Steinmetz E, Lobaccaro JM, Alves G, Menicacci A, Vachenc S, Solary E, Gambert P, Masson D (2009) Induction of transglutaminase 2 by a liver X receptor/retinoic acid receptor alpha pathway increases the clearance of apoptotic cells by human macrophages. Circ Res 105:393-401.

Reed-Geaghan EG, Savage JC, Hise AG, Landreth GE (2009) CD14 and tolllike receptors 2 and 4 are required for fibrillar $\mathrm{A} \beta$-stimulated microglial activation. J Neurosci 29:11982-11992.

Richard KL, Filali M, Préfontaine P, Rivest S (2008) Toll-like receptor 2 acts as a natural innate immune receptor to clear amyloid $\beta_{1-42}$ and delay the cognitive decline in a mouse model of Alzheimer's disease. J Neurosci 28:5784-5793.

Ruan L, Kang Z, Pei G, Le Y (2009) Amyloid deposition and inflammation in APPswe/PS1dE9 mouse model of Alzheimer's disease. Curr Alzheimer Res 6:531-540.

Sahay B, Patsey RL, Eggers CH, Salazar JC, Radolf JD, Sellati TJ (2009) CD14 signaling restrains chronic inflammation through induction of p38MAPK/SOCS-dependent tolerance. PLoS Pathog 5:e1000687.

Schmittgen TD, Livak KJ (2008) Analyzing real-time PCR data by the comparative $\mathrm{C}(\mathrm{T})$ method. Nat Protoc 3:1101-1108.

Sheng JG, Bora SH, Xu G, Borchelt DR, Price DL, Koliatsos VE (2003) Lipopolysaccharide-induced-neuroinflammation increases intracellular accumulation of amyloid precursor protein and amyloid beta peptide in APPswe transgenic mice. Neurobiol Dis 14:133-145.

Simard AR, Soulet D, Gowing G, Julien JP, Rivest S (2006) Bone marrowderived microglia play a critical role in restricting senile plaque formation in Alzheimer's disease. Neuron 49:489-502.

Tahara K, Kim HD, Jin JJ, Maxwell JA, Li L, Fukuchi K (2006) Role of toll-like receptor signalling in Abeta uptake and clearance. Brain 129:3006-3019.

Tan J, Town T, Mori T, Wu Y, Saxe M, Crawford F, Mullan M (2000) CD45 opposes $\beta$-amyloid peptide-induced microglial activation via inhibition of p44/42 mitogen-activated protein kinase. J Neurosci 20:7587-7594.

Town T, Nikolic V, Tan J (2005) The microglial "activation" continuum: from innate to adaptive responses. J Neuroinflammation 2:24.

Town T, Laouar Y, Pittenger C, Mori T, Szekely CA, Tan J, Duman RS, Flavell RA (2008) Blocking TGF-beta-Smad2/3 innate immune signaling mitigates Alzheimer-like pathology. Nat Med 14:681-687. 